\title{
Intrapulmonary arteriovenous shunting may be a universal phenomenon in patients with the superior cavopulmonary anastomosis: a radionuclide study
} J J Vettukattil, Z Slavik, R K Lamb, J L Monro, B R Keeton, V T Tsang, A J Aldous,
A Zivanovic, S Johns, V Lewington, A P Salmon

\begin{abstract}
Objective-To evaluate the extent of intrapulmonary right to left shunting in children after bidirectional cavopulmonary anastomosis (BCPA).

Design-Prospective study of patients who underwent BCPA in a single centre.

Patients-17 patients with complex cyanotic congenital cardiac malformations who underwent BCPA at 1-45 months of age (median 21 months) were evaluated 15-64 months postoperatively (median 32 months). Five children between 1 and 10 years (median 5 years) with normal or surgically corrected intracardiac anatomy and peripheral pulmonary circulation who required V/Q scanning for other reasons were used as controls.

Interventions-All patients underwent cardiac catheterisation to exclude angiographically demonstrable venovenous collaterals followed by pulmonary perfusion scanning using ${ }^{99 \mathrm{~m}}$ technetium ${ }^{99 \mathrm{~m}} \mathrm{Tc}$ ) labelled albumen microspheres to quantify the intrapulmonary right to left shunt.

Main outcome measure-Percentage of intrapulmonary right to left shunt.

Results-The mean (SD) level of physiological right to left shunting found in the control group was $5.4(2.3) \%$. All patients with BCPA showed the presence of a significantly higher level of intrapulmonary shunting $(26.8(16.9) \%, \mathrm{p}<0.001)$. The degree of shunting was significantly increased in the subgroup of 11 patients with BCPA as the only source of pulmonary blood flow (34.9 (15.8)\%), when compared to the six remaining patients with an additional source of pulmonary blood supply $(12.0(2.6) \%, \mathrm{p}<0.001)$. There was a negative correlation between age at $\mathrm{BCPA}$ and the shunt percentage found in the patients with a competitive source of pulmonary blood flow $(r=-0.63, \mathrm{p}<0.01)$.

Conclusions-Intrapulmonary right to left shunting develops in all patients following BCPA. This may be caused by a sustained and inappropriate vasodilatation resulting from absence or decreased levels of a substance that inhibits pulmonary vasodilatation. Augmenting BCPA with an additional source of blood flow containing hepatic factor limits the degree of intrapulmonary arteriovenous shunting and may help provide successful longer term palliation.
\end{abstract}

(Heart 2000;83:425-428)

Keywords: congenital heart defects; cavopulmonary anastomosis; pulmonary arteriovenous malformations; radionuclide scan

The superior bidirectional cavopulmonary anastomosis (BCPA) has an established place in the management of patients with complex cyanotic congenital heart disease, but progressive systemic desaturation limits the period of palliation. The aetiology of this is poorly understood and may be multifactorial. One of the factors implicated is the development of macroscopic pulmonary arteriovenous malformations (PAVM) seen in some of these patients. ${ }^{12}$ The removal of an "hepatic factor" in the hepatic venous return from the pulmonary circulation is an appealing hypothesis that also explains the occurrence of PAVM and hypoxaemia in patients with liver disease (hepatopulmonary syndrome)..$^{3-5}$ If the integrity of the pulmonary vasculature is dependent on hepatic factor then its abrupt elimination from the pulmonary circulation after BCPA would lead to early diffusion-perfusion impairment and arteriovenous intrapulmonary shunting before the development of PAVM. The aim of our study was to look for evidence of arteriovenous shunting following BCPA in the absence of angiographic evidence of PAVM.

\section{Methods}

PATIENTS

We studied 17 patients with complex congenital cardiac malformations who underwent BCPA but had not yet proceeded to a Fontan type procedure. The age of the patients at the time of BCPA was between 1-45 months (median 21 months) (table 1). The interval between BCPA and the study was between 15-65 months (median 32 months). All patients underwent cardiac catheterisation and angiocardiography. On establishing the absence of anatomic shunts (venovenous and venoatrial) they underwent pulmonary perfusion scan using ${ }^{99 \mathrm{~m}}$ technetium $\left({ }^{99 \mathrm{~m}} \mathrm{Tc}\right.$ ) labelled albumin microspheres. Five children between 1 and 10 years with normal or surgically corrected intracardiac anatomy and peripheral pulmonary circulation who required $\mathrm{V} / \mathrm{Q}$ scanning for other reasons were used as 
Table 1 Patients with BCPA undergoing radionuclide scan

\begin{tabular}{lclll}
\hline Diagnosis & $\begin{array}{l}\text { Age at BCPA } \\
\text { (months) }\end{array}$ & $\begin{array}{l}\text { BCPA_study } \\
\text { interval (months) }\end{array}$ & $\begin{array}{l}\text { Shunt } \\
(\%)\end{array}$ & $\begin{array}{l}\text { Competitive } \\
\text { blood supply }\end{array}$ \\
\hline DILV, PA & 1 & 60 & 26 & No \\
DILV, TGA & 31 & 32 & 19 & No \\
DILV, TGA & 2 & 44 & 45 & No \\
DILV, TGA & 22 & 33 & 54 & No \\
DILV, TGA & 14 & 44 & 64 & No \\
DILV, TGA & 40 & 25 & 24 & No \\
DIRV, PA & 14 & 65 & 33 & No \\
TA & 26 & 44 & 51 & No \\
TA, VSD & 2 & 23 & 25 & No \\
DILV & 35 & 50 & 19 & Yo \\
RI, PA & 45 & 26 & 10 & Yes \\
DILV, Band & 13 & 15 & 10 & Yes \\
PA/IVS, R-BT & 37 & 31 & 12 & Yes \\
PA/IVS, B-BT & 3 & 64 & 17 & Yes \\
LI, DORV, PS & 2 & 16 & 11 & Yes \\
PA/IVS & 21 & 18 & 11 & \\
DORV, TGA & 34 & 20 & &
\end{tabular}

B-BT, bilateral Blalock-Taussig shunt; Band, pulmonary artery banding; DILV, double inlet left ventricle; DORV, double outlet right ventricle; IVS, intact ventricular septum; LI, left isomerism; PA, pulmonary atresia; PS, pulmonary stenosis; RA, right atrium; R-BT, right Blolock-Taussig shunt; RI, right isomerism; TA, tricuspid atresia; TGA, transposition of the great arteries; VSD, ventricular septal defect. blood and the shunt fraction were calculated by the Chilvers method. ${ }^{7}$ We made the usual assumption that the right kidney receives $10 \%$ of the cardiac output so that the percentage injected dose is: kidney activity $\times 10 \div$ injected activity.

The shunt fraction uses the true counts from the right kidney and the total counts from the lungs. The lung counts were calculated from the posterior and anterior views. The region for each lung was drawn on the posterior ventilation image. The regions were redisplayed on the perfusion views and the counts were noted. All counts were corrected for the ${ }^{99 \mathrm{~m}} \mathrm{Tc}$ since the injection and the geometric mean for the counts for each lung calculated from the two views. The geometric mean count is then corrected for attenuation using the thickness of the lungs. ${ }^{89}$ The shunt fraction was calculated from the following formula: right kidney counts $\times 10 \div(($ right kidney counts $\times 10)+$ total lung counts).

controls (table 1). The protocol of the study was approved by the South and West England research ethics committee and informed consent was obtained from the parents of all patients.

IMAGING TECHNIQUE

All patients were studied using an IGE-400 gamma camera with a low energy general purpose collimator. Images were acquired for about two minutes in $256 \times 256$ matrices on to a Link Medical MAPS 10000 computer. Ventilation perfusion scans were acquired for each patient. A posterior lung ventilation image was acquired using $\mathrm{Kr}^{81 \mathrm{~m}}$ breathed through a mask. Perfusion images were obtained following supine injection of ${ }^{99 \mathrm{~m}} \mathrm{Tc}$ labelled microspheres into a right arm vein. We used microaggregates of the size $8-28 \mu \mathrm{m}$ so as to enable the detection of smaller shunts. Approximately $25-35 \mathrm{MBq}$ of ${ }^{99 \mathrm{~m}} \mathrm{Tc}$ labelled microspheres were drawn up into a syringe and measured accurately in a radioisotope calibrator. After injection the residual syringe and cannula activity were measured. Anterior and posterior lung images were acquired followed by posterior and right lateral abdominal views for measuring renal depth. The imaging time was increased if the renal count rate was poor. The sensitivity of the gamma camera was measured by using a standard technique. The images were transferred to a Sun Sparcstation 2 and were analysed using locally written software (Portable Image Computer Software). ${ }^{6}$ The counts in each image were normalised to take account of variations in imaging time in individual patients. The percentage of shunted

Table 2 Control group of patients undergoing radionuclide scan

\begin{tabular}{lll}
\hline $\begin{array}{l}\text { Age } \\
\text { (years) }\end{array}$ & Diagnosis & $\begin{array}{l}\text { Shunt } \\
(\%)\end{array}$ \\
\hline 1 & Arterial correction for TGA, LPA stenosis & 3 \\
4 & Arterial correction for TGA, LPA stenosis & 7 \\
5 & Arterial correction for TGA, LPA stenosis & 3 \\
5 & Full correction for PA/VSD & 8 \\
10 & Frequent chest infection & 6 \\
\hline
\end{tabular}

LPA, left pulmonary artery; PA, pulmonary atresia; TGA, transposition of great arteries; VSD, ventricular septal defect

\section{DATA ANALYSIS}

All data are expressed as mean (SD) and range. The Wilcoxon 2 sample test was used for statistical analysis of the data and the correlation coefficient calculated where appropriate. Values of $\mathrm{p}<0.05$ were considered significant.

\section{Results}

The control group had physiological levels of intrapulmonary right to left shunting (5.4 $(2.3) \%$ ) (table 2). All patients with BCPA showed the presence of intrapulmonary shunting $(20(15.1) \%)$ significantly higher than the physiological levels $(\mathrm{p}<0.001)$ (table 1$)$. The degree of shunting was higher in the subgroup without competitive pulmonary blood flow (34.9 (15.8)\%), when compared to the subgroup with a source of pulmonary blood supply additional to the BCPA (11.8 (2.6)\%, $\mathrm{p}<0.001)$. Although the patients with an additional source of pulmonary blood flow had much less shunting, this was still higher than the level in the control group. A negative correlation was found between the age at BCPA and the shunt level in the patients with an additional source of pulmonary blood flow after BCPA $(r=-0.63, \mathrm{p}<0.01)$.

\section{Discussion}

BCPA is increasingly used for interim palliation of complex cyanotic congenital heart disease. ${ }^{2}{ }^{10}$ Excellent intermediate term palliation is achieved and the advantages over a systemic to pulmonary arterial shunt are well established. ${ }^{11-13}$ However, it is well recognised that progressive systemic arterial desaturation occurs and a number of factors have been proposed to explain this. ${ }^{14-16}$ This includes macroscopic PAVM which have long been recognised as a serious late complication of the cavopulmonary anastomosis. ${ }^{1}$ The finding of similar abnormalities in chronic liver disease lead to the suggestion that the loss of "hepatic factor" from the pulmonary circulation might be responsible for these changes. ${ }^{417}$ If loss or reduced concentrations of hepatic factor are implicated in the development of PAVM, then 
pulmonary arteriovenous shunting (a right to left shunt) should occur early following BCPA, and PAVM merely represent the end stage of the process.

Various methods are now available for the demonstration of intrapulmonary shunting. Contrast echocardiography, though employed frequently, ${ }^{18}$ has limited use as it cannot quantify the shunt or assess its progression. Lung perfusion scanning using ${ }^{99 \mathrm{~m}} \mathrm{Tc}$ labelled microaggregated albumin microspheres has been found to be highly specific in the detection of clinically significant intrapulmonary shunting. ${ }^{71} 20$ Our study confirms that lung perfusion scanning using ${ }^{99 \mathrm{~m}} \mathrm{Tc}$ labelled microaggregated albumin microspheres of only $8-28 \mu \mathrm{m}$ is a useful method for detecting and quantifying intrapulmonary shunting even at physiological levels in normal subjects.

We have shown the presence of increased intrapulmonary shunting in all patients studied (range 10-64\%) compared to the controls (3-8\%). Patients with BCPA as the only source of pulmonary blood flow had a significantly higher volume of intrapulmonary shunting compared to those with competitive pulmonary blood flow $(p<0.001)$. The degree of intrapulmonary shunting correlated well with patients' clinical status as those with more than $25 \%$ shunt have subsequently gone on to have the modified Fontan procedure completed because of progressive cyanosis. Interestingly, competitive pulmonary blood flow limited the degree of intrapulmonary shunting to low levels (range 10-17\%), but were still mildly and significantly raised compared to the controls (3-8\%). The lack of complete protection in this group may be explained by the uneven distribution of various sources of pulmonary blood supply. The BCPA provides up to $88 \%$ of blood flow to the ipsilateral lung and this may dilute the protective effect of hepatic factor from the competitive source. ${ }^{21}$ The occurrence of PAVM predominantly in the right lung following the Glenn procedure supports this hypothesis. ${ }^{1}$ Unfortunately, the technique we have employed cannot identify the degree of intrapulmonary shunting occurring in each lung, confirming only an overall reduction in pulmonary arteriovenous shunting in the presence of competitive pulmonary blood flow. This finding differs from previous studies using contrast echocardiography which have suggested that pulsatile pulmonary blood flow (competitive flow) does not have a significant effect on the development of intrapulmonary shunting. ${ }^{22}$ We believe that this reflects the difference in the methodologies used to study the shunting, as contrast echocardiography cannot determine the degree of shunting but only its presence or absence.

The negative correlation observed between the age at BCPA and intrapulmonary shunting seen in our small subgroup of patients with competitive blood flow is not inconsistent with the finding of others and may be related to the persistent primordial arteriovenous connections present in children less than 6 months of age. ${ }^{22}$ Our observation that competitive pulmonary blood flow restricted the degree of intrapulmonary shunting, irrespective of the duration of follow up, lends support to this type of approach to the surgical management of complex congenital heart defects. Moreover, we also have some evidence that later introduction of competitive blood flow to BCPA may reduce intrapulmonary right to left shunting. ${ }^{23}$ One of our patients with significant intrapulmonary shunting and desaturation after BCPA (saturation $65 \%$, shunt $45 \%$ ) improved dramatically one week after her pulmonary blood flow was augmented by a contralateral modified Blalock-Taussig shunt (saturation $80 \%$, shunt $25 \%$ ). Similar improvement of systemic arterial saturations have been observed in patients with hepatopulmonary syndrome after liver transplantation. ${ }^{24-28}$

These observations support the hypothesis that normal pulmonary vascular tone is maintained by a fine balance between stimulatory and inhibitory influences. ${ }^{29}$ We believe that the factor(s) with inhibitory effect on vasodilatation should at least in part be supplied by the liver. This hepatic factor must be largely or completely removed by the systemic circulation in its first pass, resulting in its insignificant concentration in the superior caval blood. Unopposed precapillary and capillary vasodilatation would follow in the lung or the parts perfused by the blood without hepatic factor. ${ }^{30}$ Interestingly, patients who have normal hepatocellular function but have portal vein occlusion from different causes also develop PAVM. ${ }^{31}{ }^{32}$ Even the "unusual" cases of PAVM reported in the literature in association with carcinoid syndrome had associated portal vein obstruction. ${ }^{33}{ }^{34}$ From these observations it is possible to infer that hepatic factor is under the influence of a "portal venous factor" that regulates its synthesis. We therefore propose that portal venous factor present in the portal venous blood is normally modified or eliminated by the liver. When portal venous factor either partly or fully bypasses the hepatic microcirculation, as in portal vein obstruction or portal hypertension, it would enter unmodified into the pulmonary and systemic circulation leading to systemic and pulmonary vasodilatation. Thus, the liver seems to play a crucial role in the metabolism of both hepatic factor and portal venous factor. While traversing the hepatic parenchyma, portal venous factor stimulates production or is modified into hepatic factor which inhibits vasodilatation. Imbalance in the relative concentrations of portal venous factor and hepatic factor may result in intrapulmonary shunting, PAVM, or even pulmonary hypertension.

This study helps us to understand further the pathophysiology of arteriovenous shunting following BCPA and the effect of competitive flow. It suggests that shunting is inevitable in the absence of competitive flow, but is significantly attenuated in its presence. Further studies are required to determine the rate of progression of arteriovenous shunting and the longer term role of competitive flow in their prevention. At this time the amount of competitive flow necessary to prevent the development of clinically important arteriov- 
enous shunting and the biochemical mechanisms involved remain unknown.

1 Kopf GS, Laks H, Stancel HC, et al. Thirty year follow up of superior vena cava pulmonary artery (Glenn) shunts. superior vena cava pulmonary artery
Thorac Cardiovasc Surg 1990;100:62-71.

2 Trusler GA, Williams WG, Cohen AJ, et al. The cavopulmonary shunt: evolution of a concept. Circulation 1990:82:IV-131-8.

3 Barbe T, Losay J, Grimon G, et al. Pulmonary arteriovenous shunting in children with liver disease. F Pediatr 1995;126: 571-9.

4 Hopkins WE, Waggoner BA, Barzilai B. Frequency and sig nificance of intrapulmonary right to left shunting in end stage hepatic disease. Am f Cardiol 1992;70:516-19.

5 Kures PR, Soble JS, Nermann A, et al. Frequency of intrapulmonary shunt detected by contrast echocardiography in advanced liver disease. $\mathcal{F} \mathrm{Am}$ Soc Echocardiogr 1994;7:27E.

6 Fleming JS, Britten A, Perring S, et al. A general software package for the handling of medical images. 7 Med Eng Tech 1991;16:162-9.

7 Chilvers ER, Peters AM, George P, et al. Quantification of right to left shunt through pulmonary arteriovenous malformations using ${ }^{99} \mathrm{Tc}^{\mathrm{m}}$ albumin microspheres. Clin Rad 1988;39:611-4

8 Fleming JS. Technique for contralateral subtraction in lateral lung radionuclide imaging. Med Biol Comput 1979;17:751-6.

9 Fleming JS. A technique for the absolute measurement of activity using a gamma camera and computer. Phys Med Biol 1979;24:176-80.

10 Kobayashi J, Matsuda H, Nakano S, et al. Haemodynamic effects of bi-directional cavopulmonary shunt with pulsatile pulmonary flow. Circulation 1991;84:III-219-25.

11 Salmon AP, Sethia B, Silove ED, et al. Cavopulmonary shunt as long term palliation in patients with tricuspid atresia. Eur 7 Cardiothorac Surg 1989;3:494-8.

12 Webber SA, Horvath P, LeBlanc JG, et al. Influence of competitive pulmonary blood flow on the bidirectional superior cavopulmonary shunt: a multi-institutional study. Circulation 1995;92:I-279-86.

13 Hopkins RA, Armstrong BE, Serwer GA, et al. Physiological rationale for a bi-directional cavopulmonary shunt: a versa-
tile complement to the Fontan principle. If Thorac tile complement to the Fon

14 Moore JW, Kirby WC, Madden WA, et al. Development of pulmonary arteriovenous malformations after modified Fontan operations. F Thorac Cardiovasc Surg 1989;98: 1045-50.

15 Gross GJ, Jonas RA, Castaneda AR, et al. Maturational and haemodynamic factors predictive of increased cyanosis following bi-directional cavopulmonary anastomosis. Circulation 1992;86:I-310.

16 Slavik Z, Lamb RK, Webber SA, et al. A rare cause of profound cyanosis after Kawashima modification of bidirectional cavopulmonary anastomosis. Ann Thorac Surg 1995;60:435-7.
17 Jonas RA [Invited letter]. Muster AJ. [Reply]. The importance of pulsatile flow when systemic venous return is connected directly to the pulmonary arteries. I Thorac is connected directly to the pulm
Cardiovasc Surg 1993;105:173-6.

18 Abrams GA, Jaffe CC, Hoffer PB, et al. Diagnostic utility of contrast echocardiography and lung perfusion scan in patients with hepatopulmonary syndrome. Gastroenterology 1995;109:1283-8.

19 Whyte MK, Peters AM, Hughes JM, et al. Quantification of right to left shunt at rest and during exercise in patients

20 Cloutier A, Ash JM, Smallhorn JF, et al. Abnormal distribution of pulmonary blood flow after the Glenn shunt or Fontan procedure: risk of development of arteriovenous fistulae Circulation 1985;72:471-9.

21 Reich O, Horvath P, Ruth C, et al. Pulmonary blood supply in bi-directional cavopulmonary anastomosis with pulsatile pulmonary blood flow. Heart 1996;75:513-17.

22 Bernstein HS, Brook MM, Silverman NH, et al. Development of pulmonary arteriovenous fistulae in children after cavopulmonary shunt. Circulation 1995; 92:II-309-14.

23 Knight WB, Mee RBB. A cure for pulmonary arteriovenous fistulas? Ann Thorac Surg 1995;59:999-1001.

24 Stoller JK, Moodie D, Schiavone WA, et al. Reduction of intrapulmonary shunt and resolution of digital clubbing associated with primary biliary cirrhosis after liver transplantation. Hepatology 1990;11:54-8.

25 Eriksson LS, Soderman C, Kriczon BG, et al. Normalisation of ventilation perfusion relationships after liver transplantation in decompensated cirrhosis: evidence of a hepatopulmonary syndrome. Hepatology 1990;11:54-8.

$26 \mathrm{McCloskey} \mathrm{JJ,} \mathrm{Scleien} \mathrm{C,} \mathrm{Schwarz} \mathrm{K,} \mathrm{et} \mathrm{al.} \mathrm{Severe} \mathrm{hypoxae-}$ mia and intrapulmonary shunting reversed by liver transplantation in a paediatric patient. $\mathcal{F}$ Pediatr 1991;118: 902-4.

27 Van Obbergh L, Carlier M, DeClety C, et al. Liver transplantation and gas exchange in hypoxaemic children. transplantation and gas exchange in hypo

28 Schwarzenberg SJ, Freese DK, Rebelmann WE, et al. Resolution of severe intrapulmonary shunting after liver transplantation. Chest 1993;103:1271-3.

$29 \mathrm{Liu} \mathrm{SF}$, Barnes PJ. Role of endothelium in the regulation of pulmonary vascular tone. Endothelium 1994;2:11-33.

30 Augusti AGN, Roca J, Rodriguez-Roisin R. Mechanism of gas exchange impairment in pati

31 Maggiore G, Borgna-Pignati C, Marni E, et al. Pulmonary arteriovenous fistula: an unusual complication of congenital hepatic fibrosis. F Pediatr Gasteroenterol Nutr 1983;2: tal hep.

32 Babbs C, Warnes TW, Haboubi NY. Noncirrhotic portal hypertension with hypoxaemia. Gut 1988;29:129-31.

33 Pappagianis J, Kanter RJ, Effman EL, et al. Polysplenia with pulmonary arteriovenous malformations. Pediatr Cardiol 1993;14:127-9.

34 Hussain A, Young ET, Greaves JD, et al. Intrapulmonary shunting causing hypoxaemia in a case of carcinoid syndrome. Clinical Endocrinology 1994;41:535-7. 